\title{
Serological evidence of West Nile virus infection in the horse population of northern Serbia
}

\author{
Strahinja Medić ${ }^{1}$, Rene van den Hoven ${ }^{1}$, Tamaš Petrović ${ }^{2}$, Diana Lupulović ${ }^{2}$, Norbert Nowotny $y^{3,4}$ \\ ${ }^{1}$ Department for Companion Animals and Horses, Clinic of Internal Medicine and Infectious Diseases, University of \\ Veterinary Medicine Vienna, Vienna, Austria \\ ${ }^{2}$ Scientific Veterinary Institute Novi Sad, Novi Sad, Serbia \\ ${ }^{3}$ Viral Zoonoses, Emerging and Vector-Borne Infections Group, Institute of Virology, Department of Pathobiology, \\ University of Veterinary Medicine Vienna, Vienna, Austria \\ ${ }^{4}$ Department of Microbiology and Immunology, College of Medicine and Health Sciences, Sultan Qaboos \\ University, Muscat, Oman
}

\begin{abstract}
Introduction: This study was conducted to evaluate the seroprevalence of West Nile virus (WNV) in the horse population of northern Serbia. Furthermore, it aimed to provide insight and an updated overview on the circulation of this re-emerging pathogen in this part of southeastern Europe. At the time of manuscript preparation, no clinical cases of WNV infection in horses were reported in this area.

Methodology: Between 2007 and 2011, a total of 252 equine serum samples were collected from seven different locations in northern Serbia. The presence of WNV-reactive IgG antibodies was examined by using commercial and in-house ELISAs. Selected ELISA-positive samples were re-tested by a WNV lineage 2 plaque reduction neutralization test 90\% (PRNT-90).

Results: In $28.6 \%$ of the 252 tested equine serum samples antibodies against WNV were detected. The results obtained with the in-house ELISA corresponded to the outcome of the commercial kit in $90 \%$ of the samples. All selected WNV antibody ELISA-positive samples were confirmed by PRNT-90 with neutralizing antibody titers of 1:23 to $>1: 512$.

Conclusion: This study confirms the circulation of WNV in northern Serbia. No striking regional differences in seroprevalences were identified suggesting WNV circulation also in other parts of Serbia. Distances between wetlands or forests and stud farms do not appear to have an influence on WNV seroprevalence.
\end{abstract}

Key words: West Nile virus; Seroprevalence; Serbia; Horse; ELISA; Plaque reduction neutralization test.

J Infect Dev Ctries 2014; 8(7):914-918. doi:10.3855/jidc.3885

(Received 16 June 2013 - Accepted 13 October 2013)

Copyright $(\underset{2}{2014}$ Medić et al. This is an open-access article distributed under the Creative Commons Attribution License, which permits unrestricted use, distribution, and reproduction in any medium, provided the original work is properly cited.

\section{Introduction}

In the last decades West Nile virus (WNV) was, with a few exceptions, of limited importance in Europe. This changed dramatically in 2008 when widespread epidemics occurred in the entire federal territory of Hungary including the eastern part of Austria [1,2] and in northern Italy [3], respectively. While the Italian outbreak was caused by a "classical" lineage $1 \mathrm{WNV}$ strain, the Hungarian/eastern Austrian outbreak was due to a novel lineage $2 \mathrm{WNV}$, which was introduced to Hungary in 2004 [4], most likely by migratory birds from Africa. This was the first time that a lineage $2 \mathrm{WNV}$ emerged outside Africa. In 2010, the "Hungarian/Austrian" lineage 2 WNV caused an epidemic of West Nile neuroinvasive disease (WNND) in the human population in northern Greece with 262 laboratory confirmed infections, including 197 neuroinvasive cases and 33 deaths $[5,6])$. The question arose how this virus could emerge $600 \mathrm{~km}$ southeast of Hungary, and there is growing evidence that this WNV strain spread - initially unrecognized - from Hungary via Serbia and other Balkan states to Greece. In 2010 another WNND outbreak in humans was reported in Romania with 57 confirmed cases and 5 fatalities. Interestingly, the etiologic agent of this epidemic was identified as another lineage 2 virus, closely related to the Volgograd 2007 WNV [7].

Given the complex epidemiological situation of WNV in central and southeastern Europe since 2008, and the scarce data available for the Balkan states, the goal of this study was to investigate serologically the presence or absence and the incidence/prevalence of WNV in horses in the northern part of Serbia, 
bordering both to Hungary and Romania. Horses are considered highly susceptible dead-end hosts for WNV infection; on the other hand the course of the vast majority of infections in horses is subclinical, only detectable by appropriate serological methods.

WNV is a widely distributed infectious agent. Taxonomically it has been listed within the Japanese encephalitis sero-complex of the family Flaviviridae [8]. Data on seroprevalence of this virus varies, as well as disease outbreaks in Europe, which have been reported in the past 30 years [9]. Serological surveys, conducted in Croatia [10] and Romania [7], Serbia's neighboring countries, showed seroprevalence rates from $0.4 \%$ up to $33.5 \%$, respectively. The first serological survey of WNV in Serbia found $12 \%$ of 349 tested horses positive [11]. The current study was conducted to evaluate the seroprevalence of WNV within the horse population of the northern part of Serbia. In addition, a more detailed overview on the circulation of this re-emerging pathogen in this part of southeastern Europe is provided. Until the time of submission of this mansucript, no clinical cases of WNV infection in horses were reported from Serbia. The first outbreak of WNND in humans in Serbia including fatal cases was observed during 2012 and published in 2013 [12].

\section{Methodology}

Between 2007 and 2011, a total of 252 equine serum samples were collected from seven different locations in northern Serbia. Horses included in this survey were of different breeds and different ages. Samples were collected from each horse in the sampled herd. None of the sampled horses showed clinical signs of illness at the time of sampling.

The presence of WNV IgG antibodies was examined by employing the commercially available ELISA kit INGEZIM West Nile COMPAC (Ingenasa, Madrid, Spain) according to the manufacturer's recommendations. In order to exclude intra-test variations all samples were re-tested with this ELISA. In addition, 101 randomly selected samples were tested in parallel by an in-house ELISA [13]. The inhouse ELISA test is based on the WNV E protein produced in Trichoplusia ni larvae, using a Baculovirus expression system [13].

Due to the known cross reactivity between WNV and other flaviviruses, selected ELISA-positive samples $(\mathrm{n}=48)$ were re-tested by WNV lineage 2specific PRNT-90 as previously described $[14,15]$.

Evaluation of sensitivity and specificity of the assays: True positive samples were defined as samples confirmed by the gold-standard PRNT-90. True negative samples were defined as samples which were negative in both rounds of analyses with the commercial WNV ELISA kit.

\section{Results}

Of the 252 equine serum samples tested in this survey, $28.6 \%$ showed antibodies against WNV. Although some differences in the seroprevalence rates were observed between the seven investigated geographic regions (Figure 1, Table 1), these differences were statistically not significant $(\mathrm{p}=$ 0.238 ).

The highest percentage of WNV-seropositive samples was recorded within the horse population of Vršac region. The lowest seroprevalences were found in Surduk and Karadjordjevo regions. The repeatability of the commercial ELISA test was $100 \%$.

Figure 1. Districts of Serbia. Areas where the samples were obtained are labeled in black.

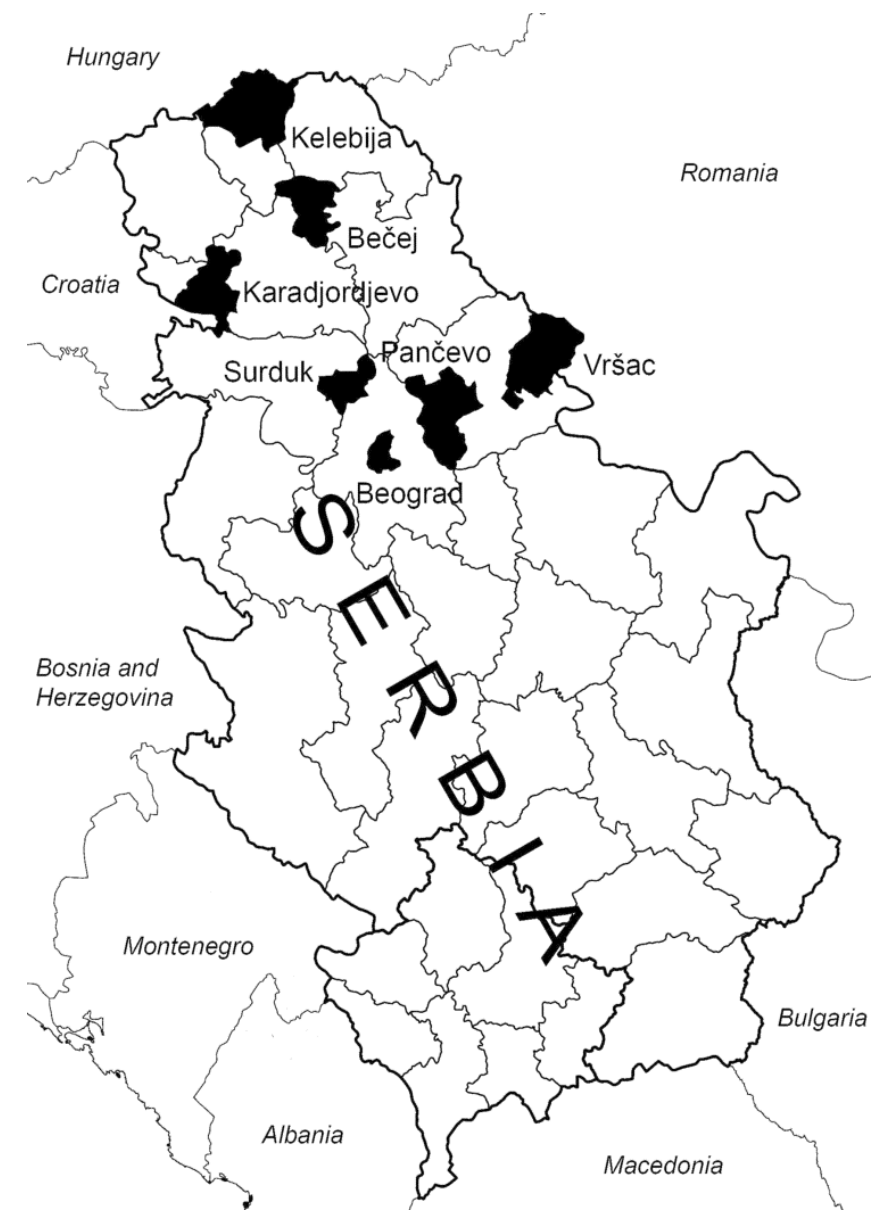


Table 1. Localization of sampled horses, number of investigated and WNV-positive samples.

\begin{tabular}{cccc}
\hline Location & Number tested & Number positive & Percentage positive \\
\hline Bečej & 32 & 7 & $21.9 \%$ \\
Kelebija & 36 & 12 & $33.3 \%$ \\
Karadjordjevo & 21 & 3 & $14.3 \%$ \\
Surduk & 30 & 4 & $13.3 \%$ \\
Pančevo & 45 & 16 & $35.5 \%$ \\
Vršac & 45 & 18 & $40.0 \%$ \\
Beograd & 43 & 12 & $27.9 \%$ \\
Total & $\mathbf{2 5 2}$ & $\mathbf{7 2}$ & $\mathbf{2 8 . 6 \%}$ \\
\hline
\end{tabular}

Table 2. Comparison of results obtained with commercial and in-house ELISA.

\begin{tabular}{lccc} 
& True & False & \\
\hline Commercial ELISA & 34 & 5 \\
In-house ELISA & 57 & 5 & 5 \\
\hline
\end{tabular}

Table 3. Results obtained by different methods.

\begin{tabular}{lccc}
\hline & Number tested & Number positive & Percentage positive \\
\hline Commercial ELISA & 252 & $\mathbf{7 2}$ & $\mathbf{2 8 . 6}$ \\
In-house ELISA & 101 & 35 & $\mathbf{3 4 . 6 5}$ \\
PRNT (on positive samples) & 48 & $\mathbf{4 8}$ & $\mathbf{1 0 0}$ \\
\hline
\end{tabular}

Figure 2. Distribution pattern of neutralizing antibody titer in horse sera from northern Serbia, tested by plaque reduction neutralization test $90 \%$ (PRNT-90).

\section{PRNT - 90 WNV lineage 2}

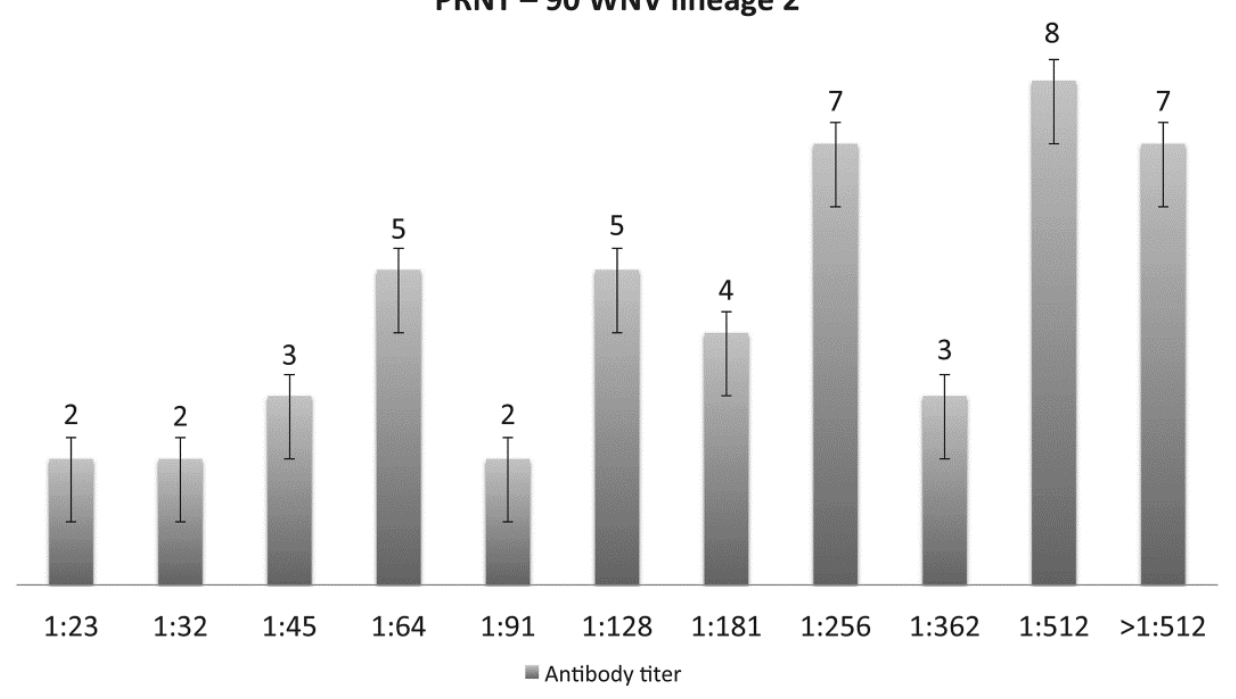


The results obtained with the in-house ELISA corresponded $90 \%$ to the outcome of the commercial ELISA. The comparative analysis of the results of the in-house ELISA and the commercial test kit is shown in Table 2. The in-house ELISA revealed a sensitivity of $87 \%$ and a specificity of $92 \%$ in relation to the commercial ELISA test.

Table 3 shows comparatively the results obtained with the various methods employed. The randomly selected 48 ELISA-positive sera were all confirmed by PRNT with titers of 1:23 to $>1: 512$. Antibody titers higher than 1:128 were discovered in more than half of the seropositive horses (Figure 2).

\section{Conclusions}

The survey presented in this paper confirmed the widespread presence of WNV-specific antibodies in the equine population of northern Serbia. The WNV antibody prevalence in the tested horse populations accounted for $28.6 \%$, thus roughly one out of three horses had experienced WNV infection at least once in its life. The equine population included in this survey was mainly of local origin and did not move outside the examined area. Only few animals had a history of travelling abroad. Since no striking regional differences were observed in the antibody prevalences, it seems justified suggesting WNV circulation throughout Serbia. The seroprevalence rate described in the first equine survey for WNV antibodies in Serbia was calculated with $12 \%$ in 349 tested horses [11]. The results of the current survey show a higher antibody prevalence in the horse population tested, almost double, which might be due to sampling of different herds and horse populations. The distances between wetlands or forests and stud farms do not appear to influence WNV seroprevalence. Distances from herd locations to wild bird nesting areas seem also to have no influence on horse WNV seroprevalences. In two horse groups (Surduk, Karadjordjevo) a lower seropositivity rate was detected. These animals spent actually less time in outdoor paddocks or were continuously kept in boxes without direct outdoor contact. To summarize, this study confirms a widespread circulation of WNV in northern Serbia. In order to be able to predict future outbreaks in the human or equine population, WNV surveillance activities in humans, susceptible animal species as well as mosquitoes should be implemented and maintained.

\section{Acknowledgements}

We thank Dr J. C. Saiz for kindly providing us with WNV recombinant $\mathrm{E}$ antigen.

\section{References}

1. Bakonyi T, Ferenczi E, Erdélyi K, Kutasi O, Csörgő T, Seidel B, Weissenböck H, Brugger K, Bán E, Nowotny N (2013) Explosive spread of a neuroinvasive lineage 2 West Nile virus in Central Europe, 2008/2009. Vet Microbiol 165: 61-70.

2. Wodak E, Richter S, Bagó Z, Revilla-Fernández S, Weissenböck H, Nowotny N Winter P (2011) Detection and molecular analysis of West Nile virus infections in birds of prey in the eastern part of Austria in 2008 and 2009. Vet Microbiol 149: 358-366.

3. Savini G, Monaco F, Calistri P, Lelli R. (2008) Phylogenetic analysis of West Nile virus isolated in Italy in 2008. Euro Surveill 13: 19048.

4. Bakonyi T, Ivanics E, Erdelyi K, Ursu K, Ferenczi E, Weissenbock H, Nowotny N (2006) Lineage 1 and 2 strains of encephalitic West Nile virus, central Europe. Emerg Infect Dis 12: 618-623.

5. Danis K, Papa A, Theocharopoulos G, Dougas G, Athanasiou M, Detsis M, Baka A, Lytras T, Mellou K, Bonovas S, Panagiotopoulos T (2011) Outbreak of West Nile virus infection in Greece. Emerg Infect Dis 17: 1868-1872.

6. Papa A, Bakonyi T, Xanthopoulou K, Vázquez A, Tenorio A, Nowotny N (2011) Genetic characterization of West Nile virus lineage 2. Emerg Infect Dis17: 920-922.

7. Sirbu A, C., Sirbu A, Celanu CS, Panculescu-Gatej R, Vazquez A, Tenorio A, Rebreanu R, Niedrig M, Nicolescu G, Pistol A (2010) Outbreak of West Nile virus infection in humans. Euro Surveill 16 pii: 19762.

8. Castillo-Olivares J, Wood J. (2004) West Nile virus infection of horses. Vet Res 35: 467-483.

9. Calistri P, Giovannini A, Hubalek Z, Ionescu A, Monaco F, Savini G, Lelli R (2010) Epidemiology of West Nile virus in Europe in the Mediterranean basin. Open Virol J 4: 29-37.

10. Madić J, Savini G., Di Gennaro A, Monaco F, Jukić B, Kovač S, Rudan N, Listes E (2007) Serological evidence for West Nile virus infection in horses in Croatia. Vet Rec 160: 772773.

11. Lupulovic D, Martín-Acebes MA, Lazic S, Alonso-Padilla J, Blázquez A-, Escribano-Romero E, Petrovic T, Saiz JC (2011) First serological evidence of West Nile virus activity in horses in Serbia. Vector Borne Zoonotic Dis 11:1303-1305.

12. Popović N, Milošević B, Urošević A, Poluga J, Lavadinović L, Nedelijković J, Jevtović D, Dulović O (2013) Outbreak of West Nile virus infection among humans in Serbia, August to October 2012. Euro Surveill 18(43). pii: 20613.

13. Alonso-Padilla J, Jiménez de Oya N, Blázquez A-, LozaRubio E, Escribano JM, Saiz J, Escribano-Romero E (2010) Evaluation of an enzyme-linked immunosorbent assay for detection of West Nile virus infection based on a recombinant envelope protein produced in Trichoplusia ni larvae. J Virol Methods 166: 37-41.

14. Sikutová $\mathrm{S}$, Hornok S, Hubálek Z, Dolezálková I, Juricová Z, Rudolf I (2009) Serological survey of domestic animals for tick-borne encephalitis and Bhanja viruses in northeastern Hungary. Vet Microbiol 135: 267-271.

15. Rushton JO, Lecollinet S, Hubálek Z, Svobodová P, Lussy H, Nowotny N (2013) Tick-borne encephalitis virus in horses, Austria, 2011. Emerg Infect Dis 19: 635-637. 


\section{Corresponding author}

Strahinja D Medić

University of Veterinary Medicine Vienna, Vienna, Austria

Phone: +381638002728

Fax: +381113808905

Email: strmbg@gmail.com

Conflict of interests: No conflict of interests is declared. 